\title{
Prevalence of Vitamin D Deficiency among Hemodialysis Patients in Palestine: A Cross-Sectional Study
}

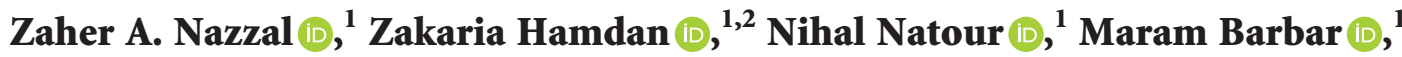 \\ Rawan Rimawi, ${ }^{1}$ and Eziyeh Salaymeh ${ }^{1}$ \\ ${ }^{1}$ Department of Medicine, Faculty of Medicine and Health Sciences, An-Najah National University, \\ Nablus 44839, State of Palestine \\ ${ }^{2}$ Department of Nephrology, An-Najah National University Hospital, Nablus 44839, State of Palestine
}

Correspondence should be addressed to Zaher A. Nazzal; znazzal@najah.edu and Zakaria Hamdan; z.hamdan@najah.edu

Received 21 October 2020; Revised 4 March 2021; Accepted 8 March 2021; Published 15 March 2021

Academic Editor: Franca Anglani

Copyright ( ) 2021 Zaher A. Nazzal et al. This is an open access article distributed under the Creative Commons Attribution License, which permits unrestricted use, distribution, and reproduction in any medium, provided the original work is properly cited.

\begin{abstract}
Introduction. The level of vitamin D status and its relationship to kidney function and liver function among patients with and without type 2 diabetes were not studied among Palestinian hemodialysis patients before. The aim of this study was to assess the status of vitamin D in hemodialysis patients with and without type 2 diabetes and its determinants. Methods. Data were collected on 163 patients on hemodialysis therapy in the Nephrology Department at Najah National University Hospital. Information on age, sex, plasma $25(\mathrm{OH}) \mathrm{D}$, serum calcium, serum phosphate, parathyroid hormone, dialysis period, hypertension, diabetes, ALT, AST, albumin, alkaline phosphates, and BMI was obtained from the medical records. Data were analyzed using SPSS. Findings. The mean level of $25(\mathrm{OH}) \mathrm{D}$ was $17.3 \pm 10.5 \mathrm{ng} / \mathrm{ml}$. Only $12.9 \%$ of subjects had $25(\mathrm{OH}) \mathrm{D}$ levels $>30 \mathrm{ng} / \mathrm{ml}$, whereas $65 \%$ had levels between 10 and $30 \mathrm{ng} / \mathrm{ml}$; the remaining $22.1 \%$ were severely vitamin $D$ deficient $(<10 \mathrm{ng} / \mathrm{ml})$. Vitamin D deficiency was more prevalent among females. It was not related to PTH, calcium, kidney, or liver function tests. Conclusion. Vitamin D deficiency is highly prevalent among patients on hemodialysis with or without DM2.
\end{abstract}

\section{Introduction}

Vitamin $\mathrm{D}$ is a hormonal vitamin that exerts its function through endocrine [1] and paracrine manner [2]. In nucleus, vitamin $\mathrm{D}$ performs its function through vitamin $\mathrm{D}$ receptors that modify many genes' transcription. Vitamin D's primary role is to change calcium absorption and metabolism with a net increase in bone mineral density, the classical function of vitamin D [3]. However, it has many other roles, including its novel function in insulin resistance and secretion, with some studies indicating a protective role for vitamin D from diabetes mellitus (DM) [4].

Renal and extrarenal enzymatic pathways exist for the activation of vitamin $\mathrm{D}$ and calcitriol production, which is the most active form of vitamin D [4]. Calcitriol and parathyroid hormone (PTH), among others, are associated with tight regulation of ionized calcium. Optimal levels of both 25-hydroxyvitamin $\mathrm{D}$ and calcitriol are associated with improved calcium and phosphorus homeostasis [5].

Patients on hemodialysis usually have low vitamin D status [6] and higher PTH [7]. Metabolic disturbances in vitamin D status and PTH in hemodialysis patients are associated with increased mortality and decrease in the quality of life [8], and hence the use of supplementation among dialysis patients is common. Despite 1,25 -vitamin D supplements, many patients with ESRD on dialysis will develop reduced bone mineral density [9]. Vitamin D supplementation in the form of calcitriol and paricalcitol improves patients' survival on hemodialysis [10]. Patients on hemodialysis in NHANES III have higher mortality from cardiovascular disease associated with vitamin D deficiency [11], which is linked to vitamin D underlying conditions such as hypertension, insulin resistance, diabetes, and dyslipidemia $[12,13]$. 
Diabetes mellitus (DM2) is the seventh cause of mortality among the Palestinian population, and according to the Palestinian bureau of statistics, $9.1 \%$ of the Palestinian people who are between the ages of 20-79 years have DM2 [14]. DM2 has many complications, including nephropathy, which happened at a rate as high as $34.6 \%$ among patients with DM2 in Palestine [15] with the risk of developing endstage renal disease and consequent use of hemodialysis, for which there is a prevalence of 240.3 per million population [16] in the Palestine.

Nablus is part of the Occupied Palestinian Territories (OPT), where it is expected that low vitamin D status is a widely prevalent health problem despite ample sunshine. In OPT, fortification of food items such as a dairy product with vitamin $\mathrm{D}$ is not a published policy. According to the author knowledge, some marketed dairy products that may not be well purchased by the public may be supplemented with vitamin D. Hence, the goals of the study are to (1) provide preliminary data on vitamin D status and PTH levels among a group of Palestinian patients on hemodialysis with and without DM2, (2) study the association between vitamin D status and indicators of calcium homeostasis, and liver function, and (3) compare vitamin D status levels between patients with and without DM2.

\section{Materials and Methods}

In a cross-sectional study design, we evaluated the charts of 163 patients with measured plasma 25-hydroxy vitamin D $(25(\mathrm{OH}) \mathrm{D})$ as it is the best method for defining a person's vitamin D status (16). The study was conducted at the Hemodialysis Unit in the Department of Nephrology at the Najah National University Hospital (NNUH). Its dialysis unit is one of the largest hemodialysis units in the West Bank, with a capacity of 332 dialysis patients.

Information on age, sex, plasma $25(\mathrm{OH}) \mathrm{D}$, serum calcium (8.0-10.0 mg/dL) (17), serum phosphate (3-4.5 mg/ dL) (18), parathyroid hormone (10-65 mg/dL) (19), dialysis period, hypertension, DM, alanine transaminase (ALT), aspartate transaminase (AST), albumin, alkaline phosphates, and BMI was obtained from the medical records. BMI $<30$ was considered non-obese, and $\mathrm{BMI} \geq 30$ was considered obese (21). Based on clinical definitions and for purposes of interpretability, 25D levels $\geq 30 \mathrm{ng} / \mathrm{dL}$ were considered replete, whereas vitamin $\mathrm{D}$ deficiency was defined as level $<30 \mathrm{ng} / \mathrm{dL}$ and severe deficiency as levels $<10 \mathrm{ng} / \mathrm{dL}(12)$. Vitamin D levels and other minerals were measured through a blood test.

Our sample was a convenience sample of 163 hemodialysis patients. The patients who did not want to participate in the research, those on $25(\mathrm{OH})$ Vitamin D supplements, and patients with chronic liver failure were excluded. Approval from An-Najah National University Institutional Review Board (IRB) was taken. Permission from NNUH to access the data we need was obtained; no consent was taken because we did the test on a blood sample that is routinely drawn from patients.

SPSS V.20 was used to analyze data. Normally distributed variables were expressed as mean \pm standard deviation, and non-normally distributed variables were expressed as median and range (minimum and maximum). Categorical data were described as numbers and percentages. $P$ values $<0.05$ were considered statistically significant. The Kruskal-Wallis test or Chi-square tests were used to examine variation between the three groups. Since several values are not normally distributed, Spearman's rank correlation $(r)$ has been used to establish the univariate correlations between $25(\mathrm{OH}) \mathrm{D}$ and selected parameters. Linear regression analysis was conducted to assess the relationship between $25(\mathrm{OH}) \mathrm{D}$ and clinical parameter including age, sex, DM, years on dialysis, calcium, phosphorous, ALP, serum albumin, and serum PTH. Variables included in the model were selected based on previously identified predictors in the literature.

\section{Results}

3.1. Patients' Characteristics. The sample included 163 consecutive patients from NNUH hemodialysis centers. Their baseline characteristics are presented in Table 1. Mean age of patients was $57.8 \pm 15.4$, and $62.6 \%$ of patients were males. Patients were divided into three groups according to $25(\mathrm{OH}) \mathrm{D}$ levels, a serum $25(\mathrm{OH}) \mathrm{D}$ level of $<10 \mathrm{mg} / \mathrm{mL}$ was identified as vitamin $\mathrm{D}$ severe deficiency, a serum level of $\geq 10$ and $\leq 30 \mathrm{ng} / \mathrm{mL}$ was identified as deficiency, and a serum level of $>30$ was considered normal.

The mean level of $25(\mathrm{OH}) \mathrm{D}$ was $17.3 \pm 10.5 \mathrm{ng} / \mathrm{ml}$. Only $12.9 \%$ of subjects had $25(\mathrm{OH}) \mathrm{D}$ levels $>30 \mathrm{ng} / \mathrm{ml}$, whereas $65 \%$ had levels between 10 and $30 \mathrm{ng} / \mathrm{ml}$; the remaining $22.1 \%$ were severely vitamin $\mathrm{D}$ deficient $(<10 \mathrm{ng} / \mathrm{ml})$ (Figure 1).

3.2. Factors Associated with Vitamin D Deficiency. For age, no significant difference was found between the means among the 3 vitamin D groups. Compared with men, women were more likely to be severely $25(\mathrm{OH}) \mathrm{D}$ deficient (14.7 vs $34.4 \%$; $P<0.25)$. Compared to patients without diabetes, those with diabetes were more likely to be severely $25(\mathrm{OH}) \mathrm{D}$ deficient (26.5 vs $38.9 \% ; P>0.05)$. Also, those with hypertension were more likely to be severely $25(\mathrm{OH})$ $\mathrm{D}$ deficient (22.4 vs $11.1 \% ; P>0.05)$. Obese patients were more likely to be severely $25(\mathrm{OH}) \mathrm{D}$ deficient compared to patients with normal BMI $(25.4 \%$ vs $45.5 \% \quad P>0.05)$ (Table 2).

For the biochemical parameters, no significant difference was found between their means among the three vitamin D groups (Table 3).

The Spearman's rank correlation was used to assess the correlation between clinical and biochemical parameters and $25(\mathrm{OH}) \mathrm{D}$ levels. No significant correlation was found with serum levels of ALT $(r=0.1)$, AST $(r=0.132)$, calcium $(r=0)$, phosphorus $(r=0.034)$, parathyroid hormone $(r=0.003)$, ALP $(r=0.05)$, albumin $(r=0.04)$, and dialysis period $(r=0.031)$ (Table 4$)$.

Multiple linear regression model was used to assess predictors of $25(\mathrm{OH}) \mathrm{D}$ levels. Gender was found to be significantly correlated with serum $25(\mathrm{OH}) \mathrm{D}$ level (Table 5). 
TABLE 1: Background, clinical, and lab characteristics of study participants $(n=163)$.

\begin{tabular}{lc}
\hline Demographic characteristics & \\
Age & $57.8 \pm 15.4$ \\
Gender (women \%) & 37.4 \\
BMI & $22.2 \pm 4.9$ \\
\hline Comorbid conditions & \\
Diabetes (yes \%) & 50.9 \\
Hypertension (yes \%) & 87.7 \\
Years on dialysis & $4.59 \pm 3.5$ \\
\hline Laboratory test results & \\
25 (OH) vitamin D & $17.3+10.5$ \\
Calcium & $8.9 \pm 0.9$ \\
Phosphorus & $4.68 \pm 1.2$ \\
PTH & $469.5 \pm 563.3$ \\
ALP & $136.7 \pm 211.94$ \\
ALT & $9.5(3.0-44.0)$ \\
AST & $13.52 \pm 5.7$ \\
AST/ALT & $1.32+0.54$ \\
Albumin & $3.73 \pm 0.4$ \\
\hline
\end{tabular}

Results are expressed as mean \pm SD or medians (interquartile ranges) as appropriate, PTH: parathyroid hormone; ALP: alkaline phosphatase; ALT: alanine transaminase; AST: aspartate transaminase.

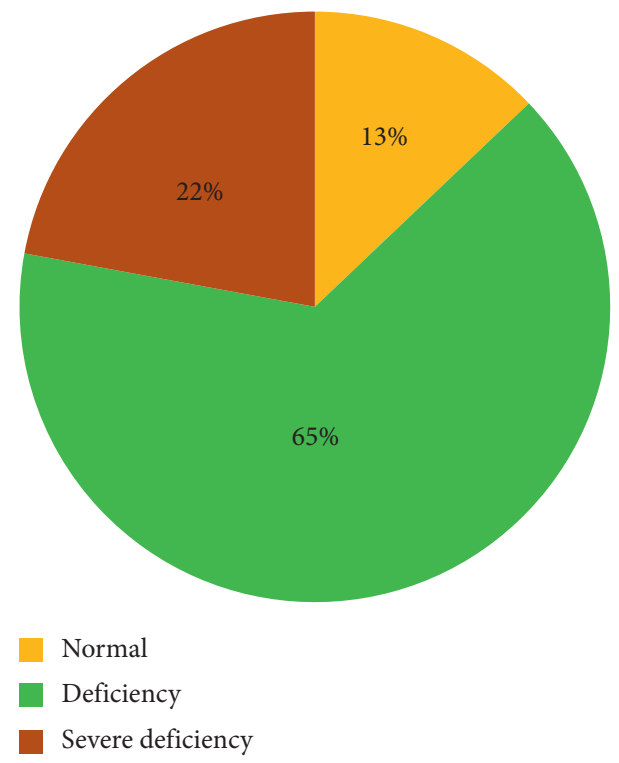

Figure 1: Distribution of $25(\mathrm{OH}) \mathrm{D}$ values among 163 hemodialysis patients.

\section{Discussion}

In a study among Palestinian patients on hemodialysis, vitamin $\mathrm{D}$ deficiency and severe deficiency were present modestly. However, vitamin D was not significantly related to PTH and serum calcium, indicating that the deficiency level possibly was associated with concurrent modification of calcium homeostasis. Among the studied groups, kidney and liver function tests were not related to vitamin $\mathrm{D}$ in the unadjusted and adjusted model (data are not shown). At the same time, vitamin D was not associated with BMI of the studied group. In this study, vitamin $\mathrm{D}, \mathrm{PTH}$, and serum calcium were higher in the group of patients without DM2, which happened to have more prolonged duration dialysis in the same group of patients.

Vitamin D level for patients without DM2 was $18.97 \mathrm{ng} /$ $\mathrm{ml}$, whereas the level for patients with DM2 was $15.7 \mathrm{ng} / \mathrm{ml}$. The high prevalence of vitamin D deficiency and insufficiency was common in our study patients, similar to what was reported among other ethnic groups [17]. In a study performed by Krause et al., patients with end-stage renal disease benefited from supplementation with vitamin D and ultraviolet (UV) radiation of the skin, with UV radiation being seven times more effective than regular supplementation [18]. In a country with ample sunshine like Palestine, located in the Middle East [19], this could be a potential way to enhance vitamin D status and, hence, the quality of dialysis patients' lives [20]. Aside from dialysis patients, reported levels of vitamin D in other groups indicate a severe deficiency in Palestine's patients, which is plausibly related to lack of clear fortification policies and few dietary resources [21].

Our study shows no significant association between PTH and vitamin D status despite high deficiency levels. PTH is known to be elevated in dialysis patients, resulting in a detrimental effect on bone health [22]. Hyperparathyroidism in patients with renal dialysis is commonly treated by active vitamin D [23]. The use of calcitriol supplementation and calcium binder to decrease phosphorus and treat high PTH could cause a lack of association between PTH and vitamin $\mathrm{D}$ status. Besides the effect of high PTH on bones, more elevated PTH is linked to CVD [24].

It is well-known that vitamin D's conversion into active calcitriol is impaired in patients with end-stage kidney diseases. This leads to an increase in PTH and a decrease in calcium absorption and reduces phosphorous excretion [25]. Data on calcitriol was not measured in our study. However, most dialysis patients need supplementation of calcitriol, or other forms of active vitamin $\mathrm{D}$. Use of active vitamin $\mathrm{D}$ in patients with dialysis is suggested to decrease oxidative stress and inflammation and decrease CVD risk [26].

In a study by Namyr et al. among 516 chronic kidney disease patients, an increment of $10 \mathrm{ng} / \mathrm{ml}$ in $25(\mathrm{OH}) \mathrm{D}$ was associated with $25 \%$ reduced mortality [27]. In another study, vitamin D supplementation was associated with $38 \%$ reduction in all-cause mortality and $45 \%$ reduction in CVD mortality [28].

In univariate analysis, there was no difference in vitamin D status among patients with or without DM2. At the same time, dialysis duration was longer in patients without DM2, and GFR was lower. Vitamin D receptor and activating enzymes were expressed in many tissues, including muscles, pancreatic cells, and other tissues implicated in insulin secretion and resistance, which were reviewed elsewhere [4].

Liver enzymes, AST and ALT, are increased in patients who undergo dialysis, as was described earlier [29]. In recent work, elevated AST/ALT ratio was associated with an increase in mortality in hemodialysis patients due to CVD, which could indicate heart tissue injury [30]. Vitamin D was not significantly related to AST/ALT ratio and the significant association with AST and ALT values 
TABLE 2: Background and co-morbidities of dialysis patients according to serum $25(\mathrm{OH}) \mathrm{D}$ levels.

\begin{tabular}{lccc}
\hline & $\begin{array}{c}\text { Severely deficient }<10 \mathrm{ng} / \mathrm{ml} \\
n=36\end{array}$ & $\begin{array}{c}\text { Deficient } 10-30 \mathrm{ng} / \mathrm{ml} \\
n=106\end{array}$ & $\begin{array}{c}\text { Normal }>30 \mathrm{ng} / \mathrm{ml} \\
n=21\end{array}$ \\
\hline Age & $59.5+13.9$ & $57.5+21.2$ & $59.2+15.4$ \\
\hline Gender & $21(34.4 \%)$ & $32(52.5 \%)$ & $8(13.1 \%)$ \\
$\quad$ Female & $15(14.7 \%)$ & $74(72.5 \%)$ & $13(12.7 \%)$ \\
$\quad$ Male & $32(22.4 \%)$ & $93(65 \%)$ & $18(12.6 \%)$ \\
\hline Hypertension & $4(11.1 \%)$ & $13(12.3 \%)$ & $3(14.3 \%)$ \\
$\quad$ Yes & $22(26.5 \%)$ & & $8(9.6 \%)$ \\
$\quad$ No & $14(38.9 \%)$ & $53(63.9 \%)$ & $13(61.9 \%)$ \\
\hline Diabetes mellitus & $53(50.5 \%)$ & $5(11.6 \%)$ \\
$\quad$ Yes & $16(37.2 \%)$ & $22(51.2 \%)$ & 0.94 \\
$\quad$ No & $20(16.7 \%)$ & $84(70.0 \%)$ & $16(13.3 \%)$ \\
\hline BMI & $4.21+3.02$ & $4.66+3.4$ & $5+4.8$ \\
$\quad$ Obese & & & 0.23 \\
$\quad$ Nonobese & & & 0.02 \\
\hline Dialysis period & & & \\
\hline
\end{tabular}

${ }^{*}$ Kruskal-Wallis test; ${ }^{* *}$ chi-square test.

TABLE 3: Markers of mineral metabolism, liver function, renal function, age, and dialysis period according to serum 25 (OH)D levels.

\begin{tabular}{lccc}
\hline & Severely deficient $<10 \mathrm{ng} / \mathrm{ml}$ & $\begin{array}{c}\text { Deficient } 10-30 \mathrm{ng} / \mathrm{ml} \\
n=36\end{array}$ & $\begin{array}{c}\text { Normal }>30 \mathrm{ng} / \mathrm{ml} \\
n=21\end{array}$ \\
\hline Calcium (mg/dL) & $n=36$ values* & $8.9 \pm 0.8$ \\
Phosphorus (mg/dL) & $8.8 \pm 0.9$ & $9.5 \pm 0.9$ & $4.5 \pm 1.2$ \\
PTH (pg/ml) & $4.6 \pm 1.0$ & $4.8 \pm 1.3$ & 0.250 \\
Alkaline phosphatase (U/L) & $498.9 \pm 485.7$ & $468.1 \pm 628.4$ & 0.743 \\
Albumin (g/dL) & $125.8 \pm 104.4$ & $140 \pm 250.9$ & 0.582 \\
AST (U/L) & $3.7 \pm 0.33$ & $3.8 \pm 0.39$ & $138.6 \pm 118.8$ \\
ALT (U/L) & $12.2 \pm 5.2$ & $13.7 \pm 5.9$ & $3.7 \pm 0.5$ \\
AST/ALT & $10.9 \pm 7.5$ & $11.9 \pm 7.1$ & $15.1 \pm 5.1$ \\
\hline
\end{tabular}

${ }^{*}$ Kruskal-Wallis test; PTH: parathyroid hormone; ALP: alkaline phosphatase; ALT: alanine transaminase; AST: aspartate transaminase.

TABLE 4: Spearman's correlation of $25(\mathrm{OH}) \mathrm{D}$ levels and various clinical and biochemical parameters.

\begin{tabular}{lcc}
\hline Parameter & Correlation coefficient & $P$ value $^{*}$ \\
\hline Age (year) & -0.21 & 0.008 \\
Dialysis period (year) & -0.016 & 0.836 \\
Calcium (mg/dL) & 0.031 & 0.836 \\
Phosphorus (mg/dL) & 0.020 & 0.799 \\
PTH (pg/dL) & 0.024 & 0.763 \\
ALP (U/L) & 0.05 & 0.530 \\
Albumin (g/dL) & 0.142 & 0.070 \\
AST (U/L) & 0.186 & 0.033 \\
ALT (U/L) & 0.199 & 0.011 \\
AST/ALT & -0.023 & 0.777 \\
\hline
\end{tabular}

*Spearman's rank tests; PTH: parathyroid hormone; ALP: alkaline phosphatase; ALT: alanine transaminase; AST: aspartate transaminase.

seem to be not clinically meaningful. ALP was notably high in our study relative to what others reported (64 $(52-82 \mathrm{U} / \mathrm{L}))$. High value is linked to high mortality in peritoneal patients, mainly related to CVD [31, 32]. Although our patients had higher ALP values, the AST, ALP, and AST/ALP values matched what others found in dialysis patients [33].

This study is not without limitations, including its crosssectional design. Intake of calcitriol and calcium binders was
TABLE 5: Multiple linear regression for predictors of $25(\mathrm{OH}) \mathrm{D}$ level.

\begin{tabular}{lccc}
\hline Constant & Beta & $R$ square & $p$ value \\
\hline Age & -0.106 & 0.086 & 0.236 \\
Gender & 0.203 & & 0.013 \\
Diabetes mellitus & -0.122 & & 0.143 \\
Dialysis duration (years) & 0.068 & & 0.417 \\
Calcium & -0.007 & & 0.932 \\
Phosphorous & 0.045 & & 0.603 \\
ALP & 0.075 & & 0.415 \\
Serum albumin & 0.023 & & 0.784 \\
Serum PTH & -0.096 & & 0.303 \\
\hline
\end{tabular}

PTH: parathyroid hormone; ALP: alkaline phosphatase.

not accounted for. In summary, in a group of patients with $\mathrm{DM} 2$ and without DM2, who receive dialysis, vitamin D deficiency was very common. Vitamin D status was not correlated with PTH. There was no association between kidney function, liver function, and vitamin D status in univariate analysis.

\section{Data Availability}

The data used to support the findings of this study are available from the corresponding author upon request. 


\section{Conflicts of Interest}

The authors declare that they have no conflicts of interest.

\section{Acknowledgments}

The authors thank all the employees of the NNUH Dialysis Unit, nurses, resident doctors, and specialists, as well as the hospital laboratory staff. The authors also thank all participants in the study.

\section{References}

[1] A. W. Norman, "From vitamin D to hormone D: fundamentals of the vitamin D endocrine system essential for good health," The American Journal of Clinical Nutrition, vol. 88, no. 2, pp. 491S-499S, 2008.

[2] M. Driel, M. Koedam, C. J. Buurman et al., "Evidence for auto/ paracrine actions of vitamin D in bone: 1a-hydroxylase expression and activity in human bone cells," The FASEB Journal, vol. 20, no. 13, pp. 2417-2419, 2006.

[3] D. D. Bikle, "Vitamin D metabolism, mechanism of action, and clinical applications," Chemistry \& Biology, vol. 21, no. 3, pp. 319-329, 2014.

[4] N. Natour, Relationships of Vitamin D Status and Markers of Skeletal Health to Metabolic Syndrome and Markers of Glucose Homeostasis Among Inuit Adults: The International Polar Year Inuit Health Survey 2007-2008, McGill University Libraries, Montreal, Canada, 2017.

[5] D. Goltzman, M. Mannstadt, and C. Marcocci, Physiology of the Calcium-Parathyroid Hormone-Vitamin D axis, in Vitamin D in Clinical Medicine, Karger Publishers, Berlin, Germany, 2018.

[6] A. R. El-Arbagy, "Assessment of vitamin D in hemodialysis patients," Menoufia Medical Journal, vol. 33, no. 1, p. 122, 2020.

[7] N. Rehman and N. Durrani, "Efficacy of cholecalciferol in the management of secondary hyperparathyroidism in hemodialysis patients," 2013.

[8] N. Elsheikh, N. Sherif, S. Abou Zeid, M. Eldamarawy, A. Ali, and A. Ismail Sabry, "The link between bone disease and cardiovascular complications in hemodialysis patients," Electronic Physician, vol. 8, no. 6, p. 2483, 2016.

[9] Y.-C. Hou, C.-L. Lu, and K.-C. Lu, "Mineral bone disorders in chronic kidney disease," Nephrology, vol. 23, pp. 88-94, 2018.

[10] Z. Zheng, "Vitamin D supplementation and mortality risk in chronic kidney disease: a meta-analysis of 20 observational studies," BMC Nephrology, vol. 14, no. 1, p. 199, 2013.

[11] I. H. de Boer, G. N. Ioannou, B. Kestenbaum, J. D. Brunzell, and N. S. Weiss, "25-Hydroxyvitamin D levels and albuminuria in the third national health and nutrition examination survey (NHANES III)," American Journal of Kidney Diseases, vol. 50, no. 1, pp. 69-77, 2007.

[12] J. P. Forman, E. Giovannucci, M. D. Holmes et al., "Plasma 25-hydroxyvitamin D levels and risk of incident hypertension," Hypertension, vol. 49, no. 5, pp. 1063-1069, 2007.

[13] A. G. Pittas, B. Dawson-Hughes, T. Li et al., "Vitamin D and calcium intake in relation to type 2 diabetes in women," Diabetes Care, vol. 29, no. 3, pp. 650-656, 2006.

[14] A. Imam, Current Status of Diabetes in Palestine: Epidemiology, Management, and Healthcare System, Springer, Cham, Switzerland, 2019.

[15] M. J. Shahwan, S. A. Gacem, and S. K. Zaidi, "Prevalence of diabetic nephropathy and associated risk factors among type 2 diabetes mellitus patients in Ramallah, Palestine," Diabetes \& Metabolic Syndrome: Clinical Research \& Reviews, vol. 13, no. 2, pp. 1491-1496, 2019.

[16] M. Khader, S. Snouber, A. Alkhatib, Z. Nazzal, and A. Dudin, "Prevalence of patients with end-stage renal disease on dialysis in the West Bank, Palestine," Saudi Journal of Kidney Diseases and Transplantation, vol. 24, no. 4, p. 832, 2013.

[17] C. Gracia-Iguacel, P. Gallar, A. R. Qureshi et al., "Vitamin D deficiency in dialysis patients: effect of dialysis modality and implications on outcome," Journal of Renal Nutrition, vol. 20, no. 6, pp. 359-367, 2010.

[18] R. Krause, "Vitamin D status in chronic kidney disease-UVB irradiation is superior to oral supplementation," Anticancer Research, vol. 36, no. 3, pp. 1397-1401, 2016.

[19] M. Mogahed, "Vitamin D status in patients with type-2 diabetes mellitus in Riyadh city, Saudi Arabia," Kasr Al Ainy Medical Journal, vol. 24, no. 1, p. 19, 2018.

[20] A. E. Grzegorzewska, A. Izdebska, L. Niepolski, W. Warchoł, and P. P. Jagodziński, "Self-reported physical activity, quality of life, and psychological status in relation to plasma 25-hydroxyvitamin d concentration in patients treated with hemodialysis," Kidney and Blood Pressure Research, vol. 41, no. 6, pp. 886-900, 2016.

[21] A. Kharroubi, "Serum 25-hydroxyvitamin D and bone turnover markers in Palestinian postmenopausal osteoporosis and normal women," Archives of Osteoporosis, vol. 12, no. 1, p. 13, 2017.

[22] J. J. Kazama and M. Wakasugi, "Parathyroid hormone and bone in dialysis patients," Therapeutic Apheresis and Dialysis, vol. 22, no. 3, pp. 229-235, 2018.

[23] T. Zhang, H. Ju, H. Chen, and W. Wen, "Comparison of paricalcitol and calcitriol in dialysis patients with secondary hyperparathyroidism: a meta-analysis of randomized controlled studies," Therapeutic Apheresis and Dialysis, vol. 23, no. 1, pp. 73-79, 2019.

[24] M. Apetrii and A. Covic, Relation Between PTH And The Risk Of Mortality In CKD, In Parathyroid Glands In Chronic Kidney Disease, Springer, Cham, Switzerland, 2020.

[25] S. N. Reddy, "The role of calcitriol in chronic kidney disease mineral bone disorder in dialysis patients," Pharmaceutical Science, vol. 8, no. 11, pp. 47-50, 2019.

[26] H. H. Yeter, "Association between calcitriol and paricalcitol with oxidative stress in patients with hemodialysis," International Journal for Vitamin and Nutrition Research, vol. 17, pp. 1-8, 2020.

[27] Y. Namir, M. Cohen, Y. Haviv, I. Slotki, and L. Shavit, "Vitamin D levels, vitamin D supplementation, and prognosis in patients with chronic kidney disease," Clinical Nephrology, vol. 86, no. 10, pp. 165-174, 2016.

[28] R. J. Lu, S. M. Zhu, F. L. Tang et al., "Effects of vitamin D or its analogues on the mortality of patients with chronic kidney disease: an updated systematic review and meta-analysis," European Journal of Clinical Nutrition, vol. 71, no. 6, pp. 683-693, 2017.

[29] I. Liberato, E. Lopes, M. Cavalcante, T. Pinto, I. Moura, and L. Loureiro-Jr, "Liver enzymes in patients with chronic kidney disease undergoing peritoneal dialysis and hemodialysis," Clinics, vol. 67, no. 2, pp. 131-134, 2012.

[30] X. Feng, "Association between aminotransferase/alanine aminotransferase ratio and cardiovascular disease mortality in patients on peritoneal dialysis: a multi-center retrospective study," BMC Nephrology, vol. 21, pp. 1-9, 2020.

[31] X. Liu, Q. Guo, X. Feng et al., "Alkaline phosphatase and mortality in patients on peritoneal dialysis," Clinical Journal 
of the American Society of Nephrology, vol. 9, no. 4, pp. 771-778, 2014.

[32] Z. Chen, "High alkaline phosphatase and low intact parathyroid hormone associate with worse clinical outcome in peritoneal dialysis patients," Peritoneal Dialysis International, vol. 41, no. 2, pp. 236-243, 2020.

[33] K. Omae, M. Yoshikawa, A. Horimoto et al., "SP651AST/ALT ratio with high normal-range ALT would be one of the most useful prognostic-factor for cardiovascular death in dialysis patients," Nephrology Dialysis Transplantation, vol. 34, no. 1, pp. gfz103-SP651, 2019. 